\title{
A Review on Phytochemical Investigation on the Stem Bark of Croton Macrostachyus
}

\author{
Bizuayehu Zinaye \\ Collage of Natural and Computational Sciences Department of Chemistry (Organic Chemistry), \\ Madda Walabu University, Po Box 247, Bale Robe, Ethiopia
}

\begin{abstract}
The Croton macrostachyus is used for the treatment of malaria, venereal diseases, cough, diabetes, constipation, tape worms and hepatitis. The dichloromethane extract of the stem bark of Croton macrostachyus was afforded two Terpenoids: the compound with full structure which is a triterpenoid and a compound with a partial structure which is a tetratrpenoid. Structural determination was accomplished by means of spectroscopic methods (IR, UV, $1 \mathrm{D}$ and 2D NMR).
\end{abstract}

Keywords: Croton macrostachyus, dichloromethane, spectroscopic methods, Terpenoids

DOI: $10.7176 / \mathrm{CMR} / 12-3-01$

Publication date:March $31^{\text {st }} 2020$

\section{INTRODUCTION}

The individual chemicals from which plants made are phytochemicals. Phytochemical study of plants is of the great importance in developing drugs. ${ }^{1}$ Drugs are strictly defined as chemical substances that are used to prevent or cure diseases in humans, animals and plants. Drugs from natural products are secondary metabolites and their derivatives. ${ }^{2}$

Natural products have been a major source of drugs for centuries, with more than $25 \%$ of the pharmaceuticals in use today derived from natural products. ${ }^{3}$ The natural products as medicinal agents presumably predate the earliest recorded history as the earliest humans used various, but specific plants to treat illness. Natural products are those chemical compounds derived from living organisms, plants, animals and insects. Until the late 1800's, organic chemistry was almost exclusively the study and use of natural products. ${ }^{4}$

Natural product chemistry is a part of organic chemistry that covers the chemistry of naturally occurring organic compounds: their biosynthesis, function in their environment, metabolism and more conventional branches of chemistry such as structural elucidation and synthesis. Primary metabolism is the system of biochemical reactions whose products are vital for the living organisms. Primary metabolic path ways often function in cycles. Secondary metabolism refers to the functions of an organism yielding products that are not necessary for the essential biochemical events. Secondary metabolites are thus compounds which are often species dependent. ${ }^{5,6}$ The secondary metabolites of organisms, including plants, serve important biological and ecological roles, mainly as chemical messengers and for defense purposes. ${ }^{7}$ Primary metabolites are essentially ubiquitous and certainly essential for life, whilst the secondary metabolites are of restricted occurrence and of no apparent utility. ${ }^{8}$ In principle, the secondary metabolites are non-essential to life but they definitely contribute to the species' fitness of survival. ${ }^{9}$ The classification of natural products, which cover almost all types of organic molecules, can be based on: chemical structure, physiological activity, taxonomy, and biogenesis. ${ }^{10}$

The World Health Organization (WHO) estimates that around $80 \%$ of the world population in developing countries relies on traditional medicines for primary health care needs, of which a major proportion corresponds to plant extracts or their active principles. ${ }^{11}$

\subsection{Croton species and their medicinal uses}

The Euphorbiaceae are mostly monoecious herbs, shrubs, and trees, sometimes succulent and cactus-like, comprising one of the largest families of plants with about 300 genera and 7,500 species that are further characterized by frequent occurrence of milk sap. ${ }^{12}$ The Species of Euphorbiaceae family are grown mainly in tropical regions. The major genera of Euphorbiaceae family are Euphorbia, Croton, Phyllanthus, Acalypha, Glochidion, Macaranga, Drypetes and Jatropha. ${ }^{13}$

The genus croton which belongs to the family Euphorbiacea and sub family crotonoideae has about 1,300 species of trees, shrubs and herbs distributed in tropical and subtropical regions of both hemispheres. In the state of Rio de Janeiro alone 39 species have been identified. The genus croton is particularly rich in secondary metabolites like alkaloids, terpenoids, and flavonoids. ${ }^{14}$ The most common class of compounds of croton is represented by diterpenoids. Apparently, clerodane is the widest spread class of diterpenoids in croton, which has been found in species from America (e. g. C. cajucara), Africa (e. g. C. macrostachyus) and Asia (e. g. C. tiglium). The genus is also rich in constituents with biological activities, chiefly diterpenoids such as labdane (1) clerodane (2), kaurane (3), trachylobane (4) and pimarane (5). Several species of the genus are aromatic, indicating the presence of volatile oil constituents. As most Euphorbiaceae, croton species may contain latex, which is red- 
coloured in some species, a characteristic usually with medicinal properties. Several croton species have a long role in the traditional use of medicinal plants in Africa, Asia and South America. Popular uses include treatment of cancer, constipation, diabetes, digestive problems, dysentery, external wounds, fever, leukemia, balsamic, narcotic, rheumatism, stomachic and tonic, bronchitis, diarrhea, leprosy, psoriasis, urtcaria, hypercholesterolemia, hypertension, inflammation, intestinal worms, malaria, pain ulcers and weight loss. Some of the croton species which are used for the treatment of such diseases traditionally in different worlds include: C. cajucara Benth., popularly known as "sacaca", C. celtidifolius Baill., commonly known as "sangue-de-adave", C. eluteria Benett., commonly known as "cascarilla", C. malambo Karst., C. nepetaefolius Baill., C. palanostigma Klotzsch, $C$. schiedeanus Schlecht., C. uraucurana Baill. , C. zehntneri Pax. Et Hoffm. (in South America), C. arboreous Millsp., C. californicus Mull. Arg., C. draco Cham. \& Schldl. (in North America and Central America), $C$. macrostachyus Hochst. ex Rich., C. zambesicus Mull. Arg (synonyms to C. amabilis Mull. Arg.; C. gratissimus Burch.) (in Africa), C. kongensis Gagnep., C. oblingifolius Roxb., popularly known as "chukka", C. sublyratus Kurz., C. tiglium L., and C. tonkinensis Gagnep, popularly called "Kho sam Bac Bo" (in Asia). The parts of those croton species which are used for medicinal purpose for treatment of different kinds of diseases are the leaves, the roots, the stem barks and the fruits. 11

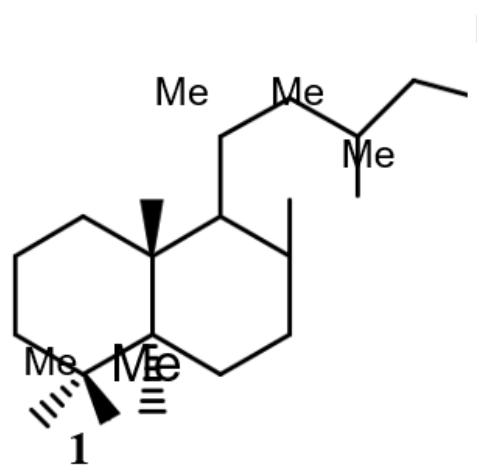

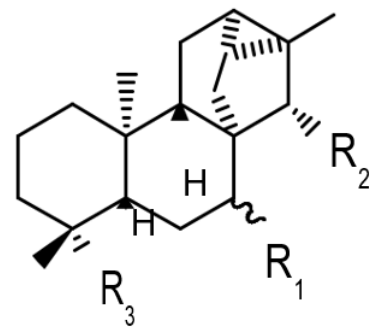

4
$\mathrm{Me}$

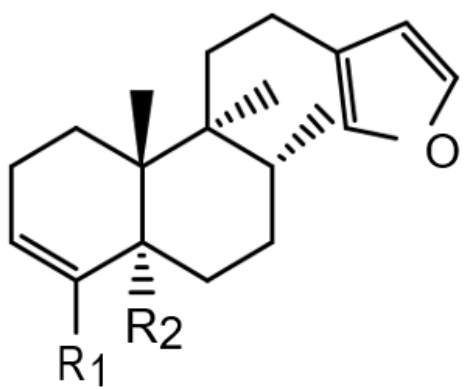

2

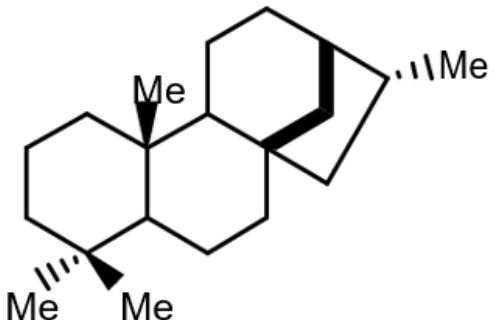

3<smiles>CCC[C@@]1(C)CC[C@H]2C(CC[C@@H]3C(C)(C)CCCC[C@@]23C)C1</smiles>

$\mathrm{Me} \mathrm{Me}$

5

\section{TERPENES}

The terpenes are ubiquitous metabolites found in all living organisms. They include essential metabolites such as the sterols acting as membrane stabilizers in eukaryotes or precursors for steroid hormones. ${ }^{15}$ They are among the most wide spread and chemically diverse groups of natural products throughout the plant and animal kingdom. They form a large and structurally diverse family of the natural products derived from $\mathrm{C}_{5}$ isoprene units joined in a head-to-tail fashion. ${ }^{17}$ These diverse, wide spread, and exceedingly numerous family of natural products are synonymously termed as terpenoids, terpenes, or isoprenoids. They are typically found in all parts (i. e., seed, flowers, foliage, roots, wood) of higher plants and also occur in mosses, liver worts, algae, and lichens, although some are of insect or microbial origin. ${ }^{8}$ Terpenes containing 30 carbons or more are usually formed by the fusion of two smaller terpene precursors such that the head-to-tail "rule" appears to be violated. ${ }^{18}$ They are found in abundance in higher plants and many terpenes occur as glycosyl esters, iridoid and triterpene glycosides being the most abundant. 19

\subsection{Classification of Terpenes}

Despite their structural diversity, terpenes have a simple unifying feature by which they are defined and by which they may be easily classified. They are group of hydrocarbon-based natural products whose structure may be derived from isoprene, giving rise to structures which may be divided into isopentane (2-methyl butane) units. Terpenes thus can be classified by the number of 5-carbon units they contain. ${ }^{1}$ These include:

Hemiterpenes $\left(\mathrm{C}_{5}\right)$

Monoterpenes $\left(\mathrm{C}_{10}\right)$ 


\section{Sesquiterpenes $\left(\mathrm{C}_{15}\right)$ \\ Diterpenes $\left(\mathrm{C}_{20}\right)$ \\ Sesterterpenes $\left(\mathrm{C}_{25}\right)$ \\ Triterpenes $\left(\mathrm{C}_{30}\right)$ \\ Tetraterpenes $\left(\mathrm{C}_{40}\right)$}

Volatile monoterpenes contribute to flavours and aromas in food and are important in perfumery. The importance of monoterpenes in flavouring has renewed interest in their biosynthesis and bioformation. The monoterpenes and their glycosides in grapes contribute to the aromas of wine. Many flavour components arise by modification of terpenes either biosynthetically or during chemical flavour generation process. ${ }^{19}$ Monoterpenes include acyclic, monocyclic, bicyclic and tricyclic types. A large percentage of them occur in higher plants as hydrocarbons, but alcohols, aldehydes, ketones, acid lactones, oxides and peroxides have been found. Most of them can be divided into head-to-tail combination of two isopentane units. ${ }^{1}$

\subsection{Biosynthesis of Terpenes}

The reaction path leading to a particular natural product is called the biosynthetic path way, and the corresponding event is known as the biogenesis. Different plant and animal species can employ dramatically different biosynthetic path ways to produce the same metabolite. This feature can be employed in the classification of plants in terms of their chemotaxonomy. ${ }^{6}$

Isoprenes had been characterized as a decomposition product from various natural cyclic hydrocarbons, and were suggested as the fundamental building block of these compounds, also referred to as 'isoprenoids'. Isoprene is produced naturally but is not involved in the formation of these compounds, and the biochemically active isoprene units were identified as the diphosphate (pyrophosphate) esters, dimethyl allyl diphosphate (DMAPP) and isopentenyl diphosphate (IPP). The biochemical isoprene units may be derived by way of intermediates mevalonic acid (MVA) or 1-deoxy-D-xylulose-5-phosphate (deoxyxylulose phosphate=DXP). ${ }^{17}$

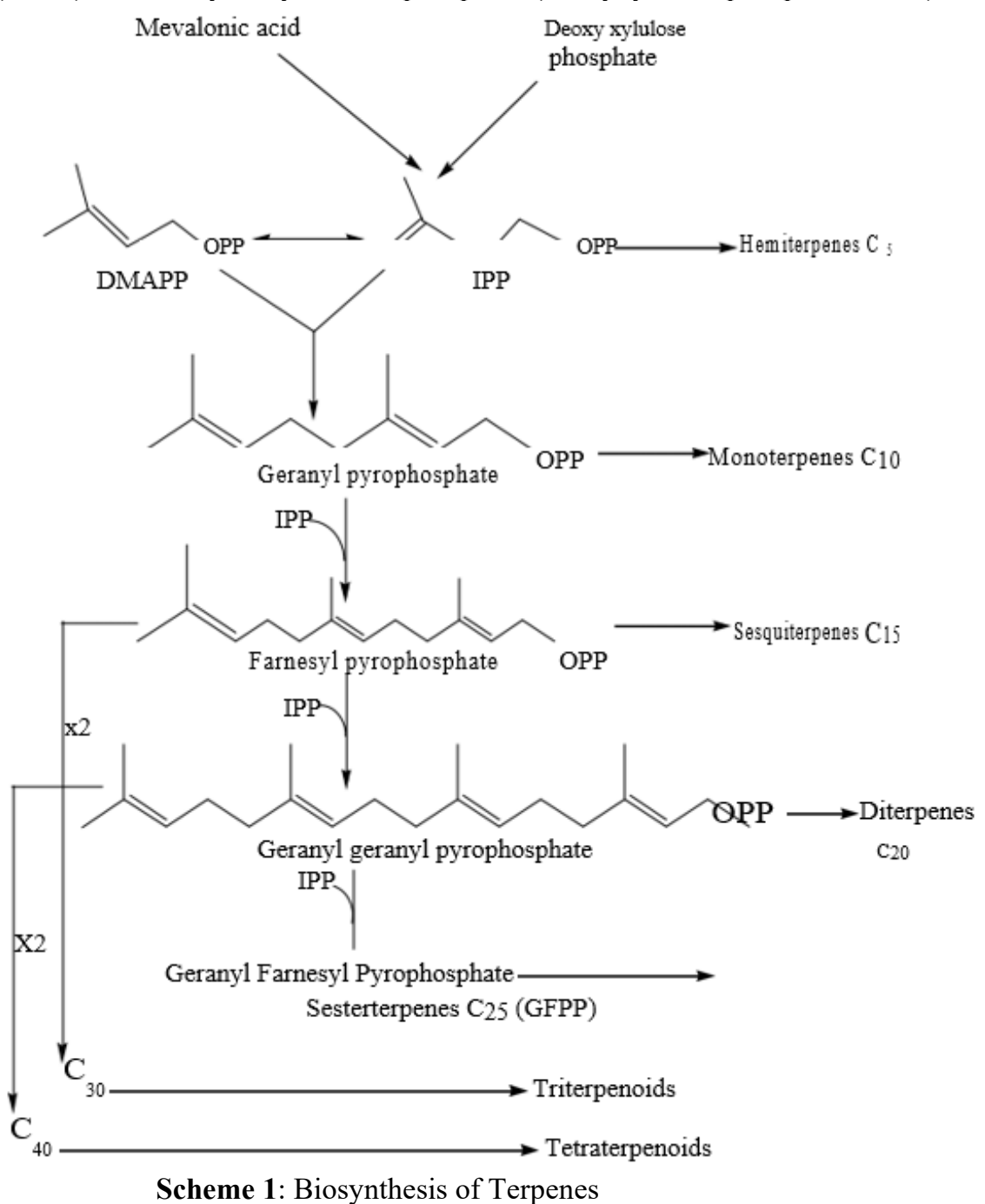




\subsubsection{Biogenesis of Isopentenyl pyrophosphate (IPP)}

Isopentenyl diphosphate (IPP), the common precursor of all isprenoids, was generally believed to arise from acetyl coenzyme A, 3-hydroxy-3-methyl glutaryl-coenzyme A and mevalonate. ${ }^{20}$ It is formed by two different biosynthetic routes, the well-known acetate (mevalonate) path way that was long and unanimously accepted as the sole biosynthetic route to IPP, and the mevalonate-independent path way starting from pyruvate and glyceraldehyde-3-phosphate yielding IPP. ${ }^{21,}{ }^{22}$ Isopentenyl and DMAPP are those reactive species which are formed from mevalonic acid by phosphorylation by ATP-assisted loss of water and carbon dioxide. ${ }^{6}$
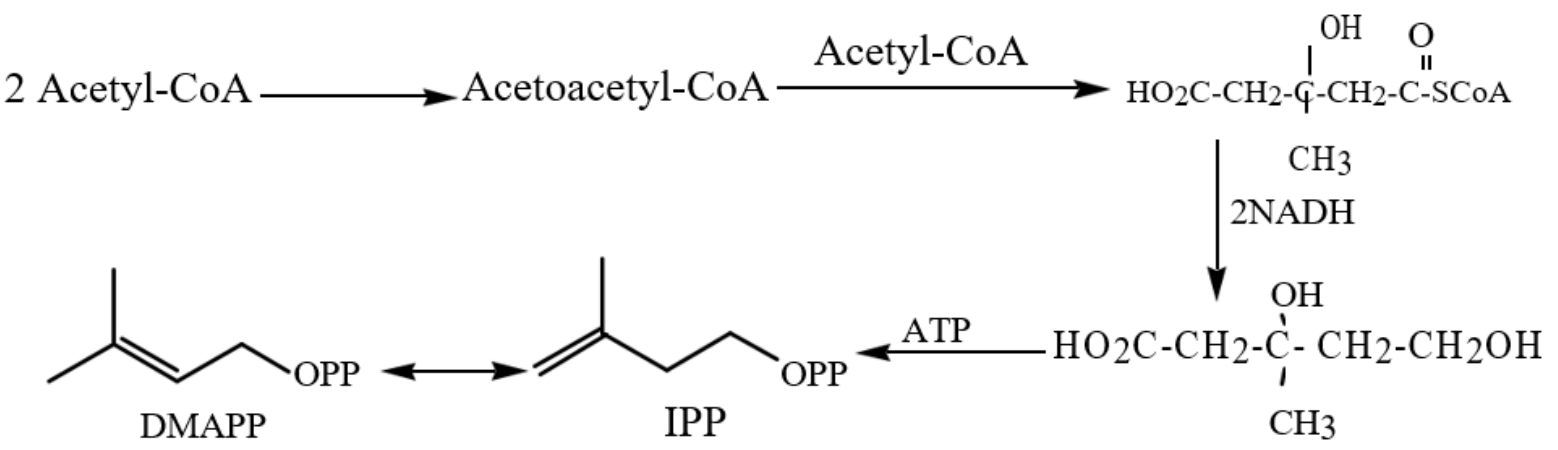

Scheme 2: Biogenesis of IPP (the Mevalonate path way)

\subsubsection{Biogenesis of Monoterpenes}

Monoterpesens are acyclic or cyclic $\mathrm{C}_{10}$ hydrocarbons and their oxygenated derivatives. They are widely used in the flavour and perfume industries because of their attractive odours, low molecular weights and high volatilities.

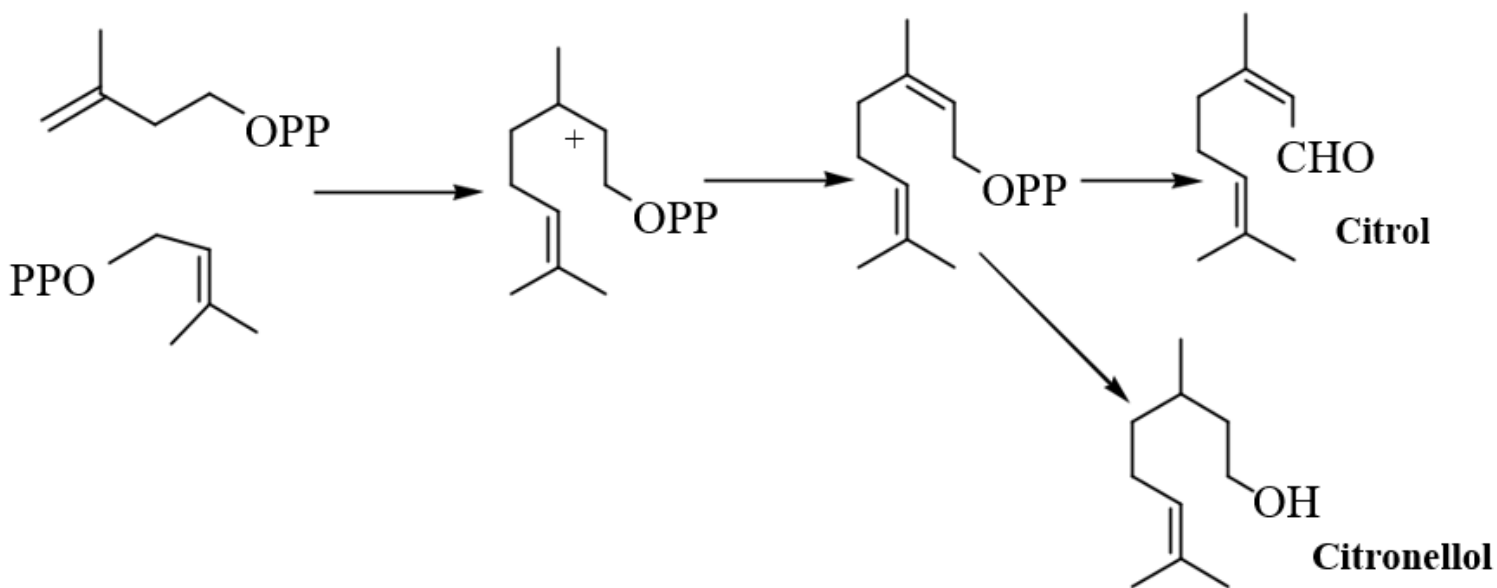

Scheme 3: Biogenesis of Monoterpenes

\subsubsection{Biogenesis of Sesquiterpenes}

Sesquiterpenes are derived from three isoprene units. They are $\mathrm{C}_{15}$ hydrocarbons or their oxygenated analogues. They exist in a wide variety of forms, including linear, bicyclic, and tricyclic frame works. Like the monoterpenes, most of them are considered to be essential oils because they belong to the stem distillable fraction often containing the characteristic odoriferous components of the plant. ${ }^{1}$ Sesquiterpenes are formed from cis-trans farnesyl pyrophosphate (FPP) through cationic cyclization reactions and subsequent rearrangement of the resulting carbonium ions. ${ }^{6,24}$ 


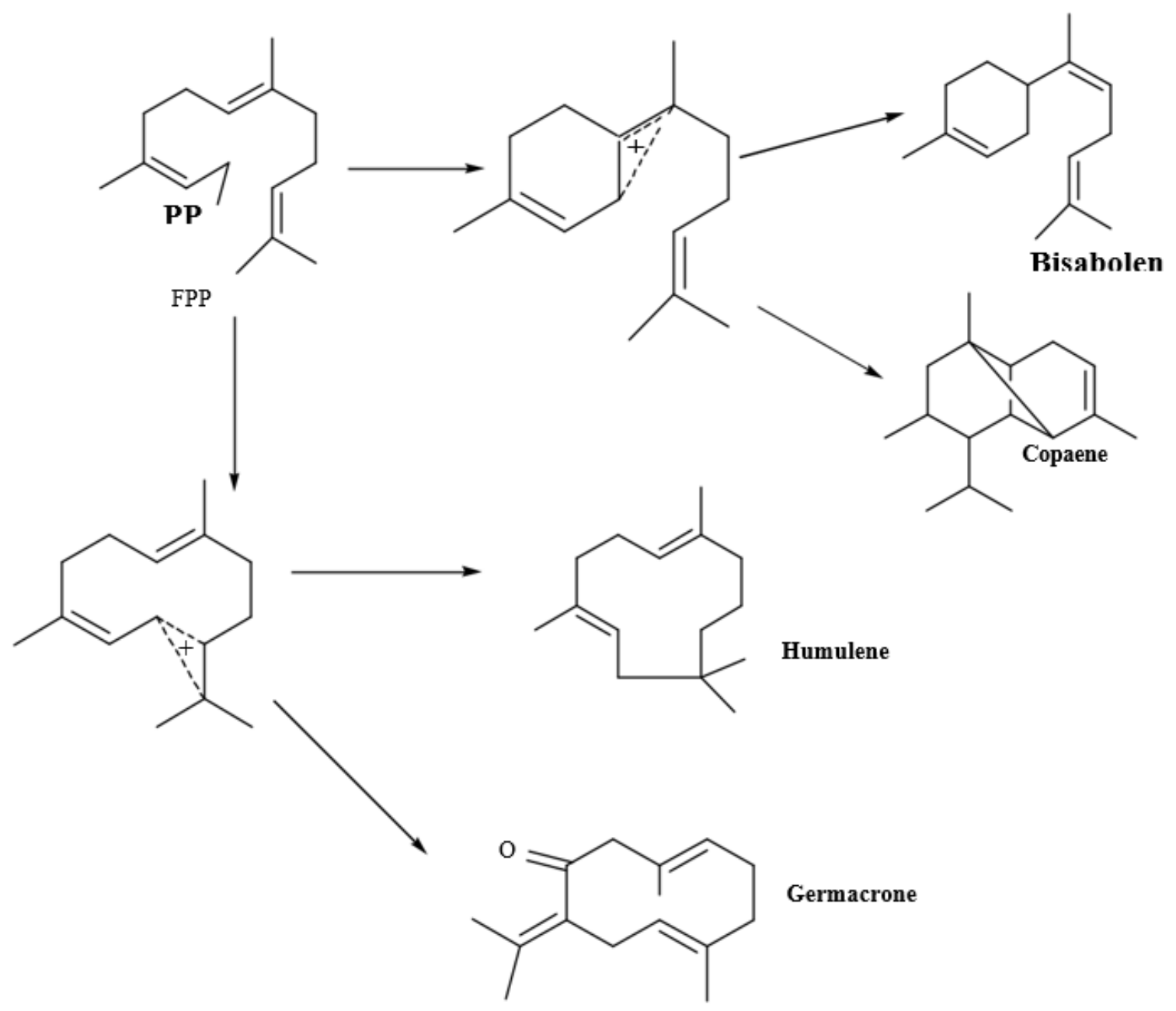

Scheme 4: Biogenesis of Sesquiterpenes

\section{CROTON MACROSTACHYUS}

\subsection{Botanical Back ground}

Croton macrostachyus which belongs to the family Euphobiaceae is a medium sized deciduous tree of East Africa particularly wide spread between $200-2500 \mathrm{~m}$ in mountainous forests and savannah of the tropical regions and ever green bush land areas that receive between $700-2000 \mathrm{~mm}$ rainfalls annually. The plant is also identified by the synonyms Croton accuminatum R. Br. and Rottlera schimperi Hochst. Ex. A. Rich. ${ }^{27}$ The generic name of the plant is derived from the appearance of the seed, for 'Croton' is based on the Greek word for a tick. The specific epithet is from the Greek macro- (large) and -stachyus (relating to spike) hence "with a large spike".

These trees experience extended flowering seasons in most areas, peaking in March-June and May-July, providing excellent bee forage. For instance, in Kenya, flowering is observed in Kakamega District in March and April; in Nyeri, Meru and Kericho Districts in June and July; and in Pokot District in August and September. In Nigeria, flowering occurs in March to May and fruiting from January to March. After pollination by insects, fruit development takes place 3-5 months. Croton macrostachyus is 3-25 m high, although more commonly 6-12 m. It is common in secondary forests, on forest edges along rivers, wood lands, wooded grass lands or clump bush land and along road sides. It is associated with Janiperus Podocarpus habitats and also occurs in the warmer parts of the montane rain forests and semi-tropical rain forests. Outside the forests, in wetter areas, the species is widely distributed. It is native to Eritrea, Ethiopia, Kenya, Tanzania, Uganda and Nigeria. Croton macrostachyus is employed in soil conservation, trees are commonly planted for the useful shade that they provide, leaf fall provides mulch and green manure; the cream-coloured, soft wood is used for indoor carpentry, furniture, veneers, tool handles, boxes and crates. ${ }^{28}$

Many parts of the croton macrostachyus have medicinal value including boiled leaf decoction is drunk or ashes taken orally as treatment for cough; juice from fresh leaves is applied on wounds to hasten clotting. Roots are used as an anthelmintic for tape worm, for malaria, venereal diseases, as antidiuretic, and the seeds are widely used as purgative, for constipation and for stomach worms. Bark from stems and roots is boiled in water and newly 
born babies are bathed in the mixture as a remedy for skin rash. The leaves of the tree are also used for fodder and the tree is used for shade. ${ }^{29}$ The stem bark and the tips of the different branches of the tree are used for the treatment of malaria and hepatitis in different parts of Ethiopia, particularly in Gojjam in the Amhara Regional State.

\subsection{Secondary Metabolites from Croton macrostachyus}

Phytochemical study on the genus Croton has lead to the isolation and characterization of different classes of secondary metabolites. Terpenes, flavonoids and alkaloids have been isolated from the different croton species. Terpenoids are the predominant secondary metabolite constituents in the genus, chiefly diterpenoids, which may belong to the clerodane, neoclerodane, kaurane, labdane, phorbol and trachylobane skeletal types. Triterpenoids, either pentacyclic or steroidal, have frequently been reported for croton species.

Table 1: Some Terpenes isolated from Croton macrostachyus

\begin{tabular}{|c|c|c|c|c|}
\hline NO. & Name of the compound & Structures & The source & Reference \\
\hline 1. & Crotomacrine & 6 & Fruits & 26 \\
\hline 2. & Crotepoxide & 7 & Fruits & 26 \\
\hline 3. & $\begin{array}{l}3 \beta \text {-acetoxy tetraxer-14-en-28-oic } \\
\text { Acid }\end{array}$ & 8 & Roots & 25 \\
\hline 4. & Trachyloban-19-oic acid & 9 & Roots & 25 \\
\hline 5. & Trachyloban-18-oic acid & 10 & Roots & 25 \\
\hline 6. & 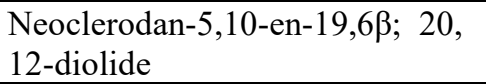 & 11 & Roots & 25 \\
\hline 7. & 3a,19-dihydroxy trachylobane & 12 & Roots & 25 \\
\hline 8. & $\begin{array}{l}3 \alpha, 18,19 \text {-trihydroxy } \\
\text { Trachylobane }\end{array}$ & 13 & Roots & 25 \\
\hline 9. & Lupeol & 14 & Root Bark & 27 \\
\hline
\end{tabular}<smiles>CC(=O)C1=CC=C[C@]2(C)[C@]1(C)CC(O)=C1C(=O)O[C@H](c3ccoc3)C[C@@]12C</smiles>

\section{Crotomacrine}

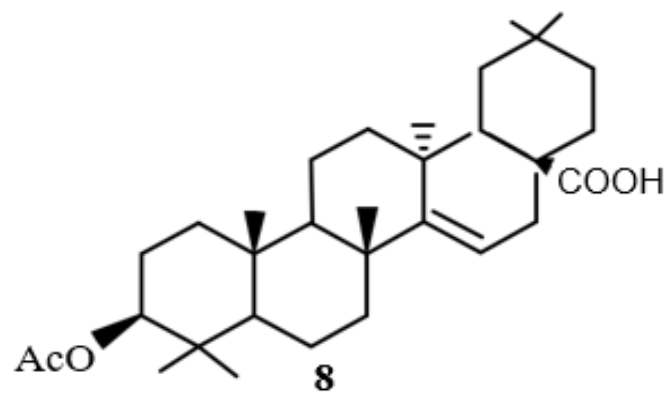

$3 \beta$-acetoxy tetraxer-14-en-28- oic acid

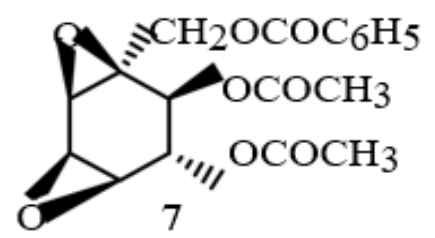

\section{Crotepoxide}<smiles>CC(=O)[C@@]1(C)CCCC2=C1[C@H](O)C[C@H](C)[C@@]21C[C@H](c2ccoc2)[C@H](C)C(=O)O1</smiles>

Trachyloban-19-oic acid 

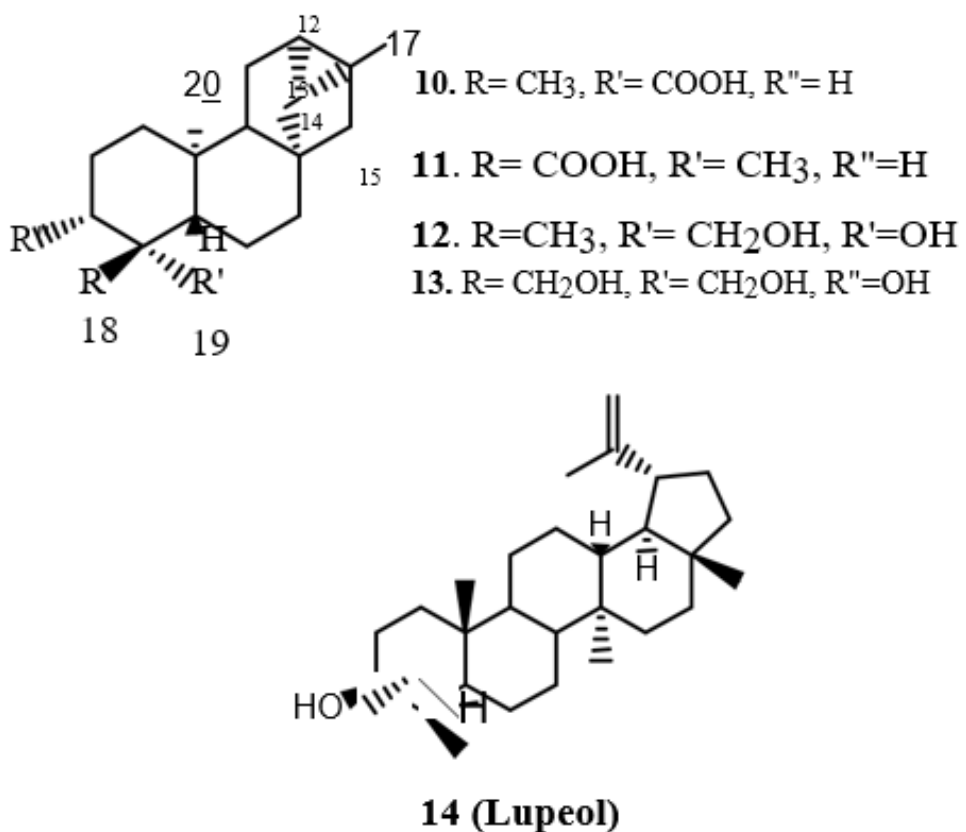

\section{Competing Interests}

The authors declare that they have no competing interests.

\section{Acknowledgments}

The authors are thankful to library and ICT office of Madda Walabu University for providing the facilities to prepare this review paper.

\section{REFERENCES}

1. Kaufman, P. B.; Cseke, L. J.; Warber, S.; Duke, J. A.; Brielmann, H. L. Natural Products from plants, CRC Press, Washington, D. C. 1999, pp. 1, 9-11

2. Thomas, G. Medicinal Chemistry, An Introduction, John Wiley and sons, Ltd., Chichester, England, 2000, pp.1

3. Williams, D. A.; Lemke, T. L. Foye's Principles of Medicinal Chemistry, Fifth edition, Lippincott Williams and Wilkins, Philadelphia, 2002, pp. 24

4. http://www. people. vcu. edu/asneden/

5. TODD, A. Natural Product Chemistry-Retrospect and Prospect, Chemistry of Natural Products International Symposium, Australia, 1960, pp. 359

5. Koskinen, A.; Asymmetric Synthesis of Natural Products, John Wiley and Sons Ltd. Chichester, England, 1993, pp. 1, 169-171

6. Sarker, S. D.; Latif, Z.; Gray, A. I. Natural Products Isolation, second edition, Humana Press Inc., Totowa, New Jersey, 2006, pp.2

8. Mann, J.; Davidson, R.S.; Hobbs, J. B.; Banthrope, D. V.; Harborne, J. B. Natural Products: their chemistry and Biological Significance, Addison Wesley Longman Ltd, England 1994, pp. 2, 289, 293

9. Torssell, K. B. G. Natural Product Chemistry, A mechanistic, biosynthetic and ecological approach, second edition, Apotekarsocieteten, Stockholm, Sweden, 1997, pp. 16-17

10. Nakanishi, K.; Goto, T.; Ito, S.; Natori, S.; Nozoe, S. Natural Produts Chemistry, Volume 1, Kodansha Ltd, Tokyo, 1974, pp. 2-4

11. Salatino, A.; Faria Salatino, M. L.; Negri, G. Journal of Brazilian Chemical Society, 2007, Vol. 18, No. 1, $11-33$

12. http://www. Botany.hawaii.edu/

13. http:/www.msu. edu/

14. http:/www. botany. wisc. edu/

15. Rohmer, M.; Seemann, M.; Horbach, S.; Bringer-Meyer, S.; Sahm, H. Journal of American chemical Society, 1996, Vol. 118, 2564

16. Bernfeld, P.; Biogenesis of Natural Compounds, The Macmillan Company, New York, 1963, pp. 641, 644, $657-658$ 
17. Dewick, P.M.; Medicinal Natural Products, A Biosynthetic Approach, Second Edition, John Wiley and Sons, Ltd. Chichester, England, 2004, pp. 167-168

18. http:/www. people. vcu. edu/

19. Thomson, R. H. The Chemistry of Natural Products, Second Edition, Blackie Academic and professional, an imprint of Chapman and Hall, UK, 1993, pp. 106-107, 111

20. Duvold, T.; Bravo, J-M.; Pale-Grosdemange, C.; Rohmer, M. Tetrahedron Letters, 1997, Vol. 38, No. 28, 4769

21. Francis, F. J. Wiley Encyclopedia of Food Science and Technology, Second Edition, Volume 1, John Wiley and Sons, Inc. New York, 2000, pp. 275

22. Cvejic, J. H.; Rohmer, M. Phytochemistry, 2000, Vol. 53, No. 1, 21

23. Asfaw, N. M. Sc. Thesis, Chemical Investigation on the essential Oils of Endemic Wild and Cultivated Lippia Adoensis, Addis Ababa University, Department of Chemistry, Addis Ababa, 1992 pp. 3

24. Teklu, S. M. Sc. Thesis, Chemical Investigation on Essential Oils of S. Abyssinica and S. Punctata, Addis Ababa University, Department of Chemistry, Addis Ababa, 1995, pp. 8

25. Kapingu, M. C.; Guillaume, D.; Mbwambo, Z. H.; Moshi, M. J.; Uliso, F. C.; Mahunnah, R. L. A. Phytochemistry, 2000, Vol. 54, No. 8, 767-770

26. Tane, P.; Tatsimo, S.; Connolly, J. D. Tetrahedron Letters, 2004, Vol. 45, 6997-6998

27. Menberu, D. M. Sc. Thesis, Chemical Composition of Croton Macrostachyus, Addis Ababa University, Department of Chemistry, Addis Ababa, 1981, pp. 2, 16

28. http:/www. worldagroforestry centre. org/

29. http:/www. york. ac. uk/res/celp/webpages/projects/ecology/ 